\title{
DIFFERENCES IN WALKABILITY INFLUENCE RESIDENTS' HYPERTENSION IN TAIWAN: AN ANALYSIS OF OPEN GOVERNMENT DATA
}

\author{
Hsin-Yen Yen \\ National Taiwan Normal University \\ No.162, Sec. 1, Heping E. Rd., Da'an Dist., Taipei City 10610, Taiwan \\ yenken520@gmail.com \\ Ching Li \\ National Taiwan Normal University \\ No.162, Sec. 1, Heping E. Rd., Da'an Dist., Taipei City 10610, Taiwan \\ t94002@ntnu.edu.tw
}

\begin{abstract}
Non-communicable diseases have become a serious problem worldwide. Disease prevention focuses on modifiable behavioral and environmental features. Walkable or pedestrian-friendly neighborhoods increase residents' physical activity and decrease the risk and mortality of non-communicable diseases. We examined walkability and the distribution of the rate of outpatients with hypertension in each administrative region in Taiwan and analyzed whether differences in walkability affect the rate of outpatients with hypertension. All data were retrieved from open government data in Taiwan and analyzed using ANOVA and the National Geographic Information System. Regions were divided into four levels, according to the standard deviation of the walkability index. There were significant regional differences in the number of outpatients with hypertension. Regions with the most walkability presented the lowest incidence of outpatients with hypertension, significantly less than incidence in the third and the least walkable regions. Thus, the lack of walkable neighborhoods is an important risk factor for hypertension. Walkable neighborhoods should be considered in urban planning and sport- and health-related policies to promote residents' well-being.
\end{abstract}

Keywords: Chronic Diseases, Physical Activity, Prevention, Health Promotion, Urban Planning 


\section{INTRODUCTION}

\subsection{Prevention of Non-communicable Diseases}

The prevention of non-communicable diseases (NCDs) is more beneficial and less costly than post-hoc control and treatment. Prevention focuses on modifiable factors, including behavioral and environmental features. Modifiable behavioral risk factors include diet, physical inactivity, and tobacco and alcohol use. ${ }^{1}$ These unhealthy behaviors can cause the elevation of blood pressure, glucose, and cholesterol, as well as weight gain and obesity, all of which lead to serious chronic diseases. ${ }^{2}$ Conversely, modifiable neighborhood features or environmental features are also associated with the risk of weight gain, obesity, and other chronic diseases, especially with regard to alternatives in food and physical activity. ${ }^{3,4}$ Physical activity is an important mediator between environment and health. ${ }^{5}$

The walkability or pedestrian-friendliness of a neighborhood affects residents' ability to engage in physical activity, especially walking. ${ }^{6}$ More studies than ever are foregrounding walkability in public health, social epidemiology, preventive medicine, health geography, and sport science. ${ }^{7}$ Walkability includes the aspects of suitability, accessibility, and proximity, including the nature of the streets, the availability of alleys, the speed of vehicles, crossable intersections, and other pedestrian services. ${ }^{8}$ Walkability influences walking, cycling, and other kinds of physical activity. ${ }^{9,}{ }^{10}$ For health promotion, people should be encouraged to walk to their destinations, because it is easy, available, and low cost. ${ }^{11}$ Walkability and the convenience of cycling are positively correlated with the continuity of physical activity, especially in transportation and recreation. ${ }^{5}$ Greater walkability could advance the volume, opportunity, and motivation of physical activity and less sedentary behavior. ${ }^{12,13}$ It is necessary to use urban design to build healthy and walkable neighborhoods. ${ }^{14}$

Previous studies have demonstrated several features of walkability in a neighborhood environment. Population/residential density, street connectivity, traffic, aesthetic, mixed land uses (e.g., the accessibility of public infrastructure, such as parks, sport facilities, shops), socioeconomic status (SES), and the crime rate are all indicators of walkability. ${ }^{6,11,12,15}$ The measurement of indicators of walkability can be subjective (e.g., perceived questionnaires) or objective (e.g., open data and geographic information systems).

Moreover, people living in pedestrian-friendly neighborhoods have reduced risk and mortality of hypertensive diseases, diabetes, metabolic diseases, arthritis, chronic diseases, and other causes of death. ${ }^{16}$ Walkable 
neighborhoods encourage healthy behavior and promotes physical and mental health. ${ }^{17}$

\subsection{Open Government Data}

Open government data (OGD) are used for policy decision making and international comparisons on social, health, and economic issues. Through the use of OGD, policies are fostered, public departments are integrated, and services in the public sector are improved. ${ }^{18}$ Usable OGD offers easily accessible, completed, and discoverable data for stakeholders and citizens. Qualified OGD need to be accurate, consistent, and renewed in a timely manner. Merging OGD from different public departments can create useful outcomes. ${ }^{19}$ OGD in Taiwan has been promoted since 2010, according to the country's E-Government Program. The open data policy was launched in 2012. The official website is a portal that links to data from the healthcare, culture, education, community development, and transportation departments.

\subsection{Purposes}

This study examined neighborhood pedestrian friendliness and the distribution of hypertensive diseases in Taiwan to determine whether different levels of walkability could influence the incidence of hypertensive diseases in counties and cities.

\section{METHOD}

\subsection{Data Collection}

All data were collected from the open data portal (data.gov.tw). OGD are supplied by the Construction and Planning Agency at the Ministry of Interior and have been updated once a year since 1997. OGD supply data in the WSDL, XML, JSON, PDF, Excel, and CSV formats. Information on the registers of land uses was incorporated, including density of streets, intersections, houses, parks, and recreational facilities. The second group of OGD is provided by the Directorate General of Budget, Accounting and Statistics (DGBAS) of the Executive Yuan and has been updated once a year since 1981. The OGD supplies data in the ODF, PDF, and Excel formats. Information on family income was incorporated. OGD are from the National Police Agency at the Ministry of Interior and have been updated once a month since 2011. The OGD supplies data in the PDF and Excel formats. Crime rates were incorporated. Finally, OGD are provided by the Department of Statistics, Ministry of Health and Welfare, Taiwan, which have been updated once a year since 1998. The OGD supplies data in the 
Excel format for non-paying subscribers. OGD on the rate of outpatients with hypertensive diseases per 100,000 population in 2014 (HTN, ICD-9 CM: A26 401-405, Health Insurance No. 0802) in 19 counties and cities in Taiwan, excluding islands, were used.

\subsection{Data Analysis}

The walkability index (WI) was calculated using the sum of the Z-score of several indicators, following previous studies, including data on street connectivity (SC), land-use mix (LUM), residential density (RD), socioeconomic status (SES), and safety (SF) (see Table 1 and Equation 1). ${ }^{11,} 16,20,21$ Based on the standard deviation of the WI, administrative regions were divided into four groups $\left(\mu^{-} \sigma^{>}\right.$WI (Region 1), $\mu^{>}$WI (Region 2) $>\mu^{-} \sigma, \mu^{+} \sigma>$ WI (Region 3) $>\mu$, WI (Region 4) $\left.>\mu^{+} \sigma\right)$ ). Region 4 had the highest walkability and Region 1 the lowest. Descriptive analysis and ANOVA were used in this study. The data analysis tools were SPSS and the National Geographic Information System (NGIS). The NGIS was provided by the government and is available free of charge to citizens and stakeholders. The NGIS is a useful platform for drawing conclusions on the information from and distribution of OGD based on administrative regions.

Table 1. The walkability index and dependent variables

\begin{tabular}{|c|c|c|c|c|}
\hline & Indicators & Contents & Unit & OGD from \\
\hline \multirow[t]{5}{*}{ WI } & $\begin{array}{l}\text { Street } \\
\text { connectivity } \\
\text { (SC) }\end{array}$ & $\begin{array}{l}\text { The density of sidewalks, } \\
\text { walkable roads, and } \\
\text { intersections }\end{array}$ & $\begin{array}{l}\% \text { of total } \\
\text { area }\end{array}$ & $\begin{array}{l}\text { Constriction and } \\
\text { Planning } \\
\text { Agency }\end{array}$ \\
\hline & $\begin{array}{l}\text { Land uses mix } \\
\text { (LUM) }\end{array}$ & $\begin{array}{l}\text { The density of parks, } \\
\text { Greenland, and } \\
\text { recreational facilities }\end{array}$ & $\begin{array}{l}\% \text { of total } \\
\text { area }\end{array}$ & $\begin{array}{l}\text { Constriction and } \\
\text { Planning } \\
\text { Agency }\end{array}$ \\
\hline & $\begin{array}{l}\text { Residential } \\
\text { density (RD) }\end{array}$ & $\begin{array}{l}\text { The density of residential } \\
\text { houses }\end{array}$ & $\begin{array}{l}\% \text { of total } \\
\text { area }\end{array}$ & $\begin{array}{l}\text { Constriction and } \\
\text { Planning } \\
\text { Agency }\end{array}$ \\
\hline & $\begin{array}{l}\text { Social } \\
\text { Economic } \\
\text { Status (SES) } \\
\end{array}$ & $\begin{array}{l}\text { The average of } \\
\text { Household incomes }\end{array}$ & $\begin{array}{l}\text { NT dollar/ } \\
\text { household }\end{array}$ & DGBAS \\
\hline & Safety (SF) & The crime rate & $\begin{array}{l}\text { times/ } \\
\text { population }\end{array}$ & $\begin{array}{l}\text { National Police } \\
\text { Agency }\end{array}$ \\
\hline DV & $\begin{array}{l}\text { Patients with } \\
\text { hypertensive } \\
\text { diseases }\end{array}$ & $\begin{array}{l}\text { The rate of outpatients } \\
\text { with hypertensive } \\
\text { diseases }\end{array}$ & $\begin{array}{l}\% \text { per } \\
100,000 \\
\text { population }\end{array}$ & $\begin{array}{l}\text { Ministry of } \\
\text { Health and } \\
\text { Welfare }\end{array}$ \\
\hline
\end{tabular}




\section{RESULTS}

\subsection{Descriptive Analysis}

Table 2 gives the results of the descriptive analysis. The indicators of WI were the following: SC was $0.409 \pm 0.097$, LUM was $1.082 \pm 1.219$, RD was $303.357 \pm 377.062$, SES was $1076088.050 \pm 23623.840$, and SF was $1164.035 \pm 329.426$. Finally, the average rate of outpatients with hypertensive diseases was $16174.512 \pm 2167.747$ per 100,000 population. The WIs were as follows: in Region 1, -3.098 \pm 0.330 ; in Region 2, $-1.216 \pm$ 0.848; in Region 3, $2.134 \pm 0.753$; and in Region 4, $4.193 \pm 0.245$.

Table 2. The result of descriptive analysis

\begin{tabular}{rlrrrr}
\hline \multicolumn{2}{c}{ Variables } & \multicolumn{1}{c}{ min } & \multicolumn{1}{c}{ Max } & \multicolumn{1}{c}{ Mean } & \multicolumn{1}{c}{ SD } \\
\hline Indicators & SC & 0.144 & 0.554 & 0.409 & 0.097 \\
& LUM & 0.062 & 5.001 & 1.082 & 1.219 \\
& RD & 61.701 & 1866.444 & 303.357 & 377.062 \\
& SES & 789406.0 & 1576797.00 & 1076088.05 & 236623.84 \\
& SF & 367.220 & 1815.400 & 1164.035 & 329.426 \\
\hline DV & HTN & 12305.819 & 19360.281 & 16174.512 & 2167.747 \\
\hline \multirow{3}{*}{ WI } & Region & & & & \\
& 1 & -3.590 & -2.900 & -3.098 & 0.330 \\
& 2 & -2.190 & -0.170 & -1.216 & 0.848 \\
& 3 & 0.900 & 2.760 & 2.134 & 0.753 \\
& 4 & 3.940 & 4.430 & 4.193 & 0.245 \\
\hline
\end{tabular}

\subsection{Differences in Walkability}

Sorted by WI, Region 1 consisted of Nantou, Hualien, Pingtung, and Chiayi County. Region 2 encompassed Yilan, Taitung, Tainan, Keelung, Changhua, Yunlin, and New Taipei. Region 3 comprised Chiayi City, Hsinchu County, Hsinchu City, Taichung, and Miaoli. Region 4 included Taipei, Taoyuan, and Kaohsiung.

Figure 1 illustrates the different walkabilities and the distributions of patients with hypertension in each administrative region using the NGIS. Regions with darker backgrounds are regions where walkability was found to be better. The sizes of the circles represent the rate of outpatients with hypertension. Regions with bigger circles were found to have a higher rate of outpatients with hypertension. Regions with darker backgrounds have smaller circles than the regions with lighter backgrounds. 


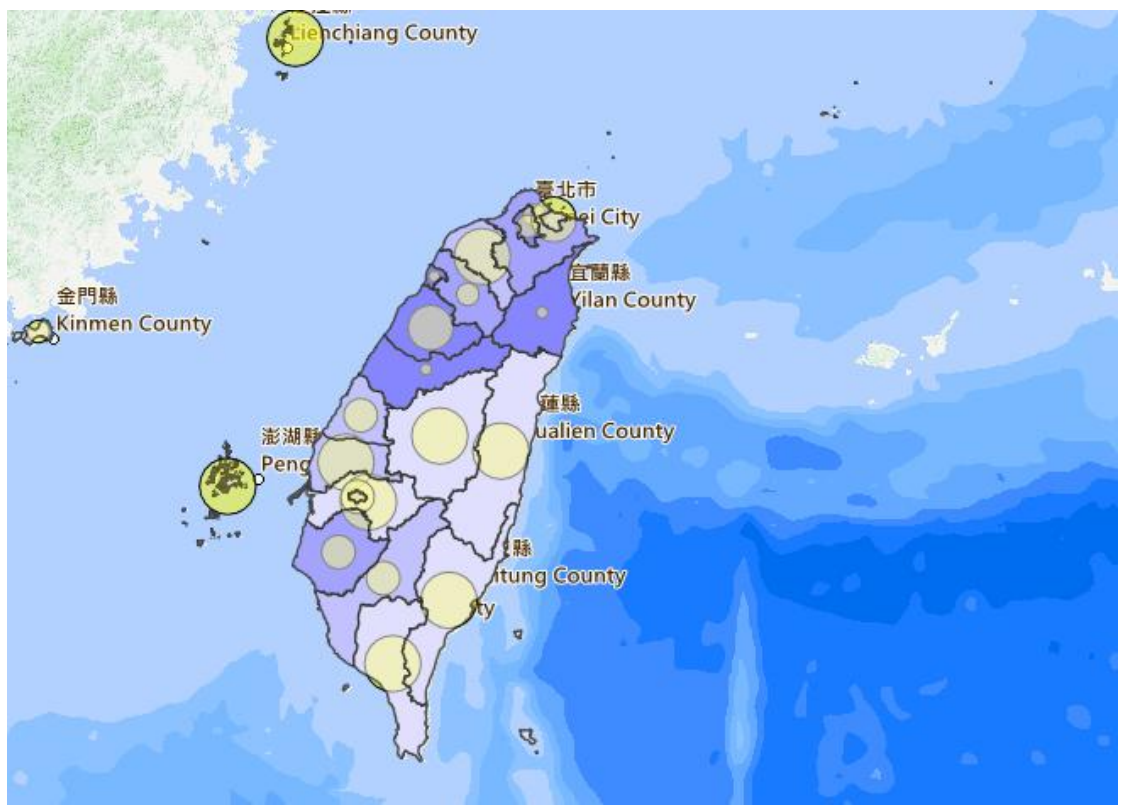

Figure 1. Results of the National Geographic Information System Visualization

ANOVA was used to examine the accuracy of the findings in the figure, and the rate of outpatients with hypertension in regions is shown in Table 3. There was a significant regional difference in the rate of outpatients with hypertension. The rates of outpatients with hypertension in Regions 1 and 2 were found to be significantly higher than in Regions 3 and 4 in the post-hoc test. Thus, more walkable regions had a lower rate of outpatients with hypertension.

Table 3. The results of ANOVA

\begin{tabular}{|c|c|c|c|c|}
\hline \multirow{2}{*}{ Region } & \multicolumn{3}{|c|}{ Outpatient rate with hypertension } & \multirow{2}{*}{$\mathbf{F}$} \\
\hline & Mean & \multicolumn{2}{|r|}{ SD } & \\
\hline 1 & 18190.019 & & 811.771 & \multirow{2}{*}{$5.825 * *$} \\
\hline 2 & 16799.565 & & 613.641 & \\
\hline 3 & 14388.761 & & 726.070 & $p$ \\
\hline 4 & 14223.350 & & 937.352 & \multirow{2}{*}{.008} \\
\hline Source & Sum of Squares & df & Mean Square & \\
\hline Between Groups & 46060164.238 & 3 & \multirow{3}{*}{$\begin{array}{r}15353388.079 \\
2635888.194\end{array}$} & Post-hoc \\
\hline Within Groups & 39538322.916 & 15 & & \multirow{2}{*}{$1,2>3,4$} \\
\hline Total & 4980716420.023 & 19 & & \\
\hline
\end{tabular}




\section{DISCUSSION}

This study demonstrated the importance of walkability in neighborhood environments. The major finding of this study was that there is a significant difference in the rate of hypertension between higher- and lower-walkability regions. Regions with higher walkability (Regions 3, 4) had a lower rate of outpatients with hypertension than regions with lower walkability (Regions 1,2). Regions 1 and 2 were largely rural, comprising areas like Nantou, Hualien, and Pingtung. A few cities in Region 2 were created by the merging of a county and city in 2010. In contrast, counties and cities in Regions 3 and 4 that had higher walkability were the capital, municipalities, and urban areas, such as Taipei, Taichung, and Kaohsiung. Urban development is different between the higher- and lower-walkability regions. The results show that walkability could explain the different distribution of residents' hypertensive diseases.

This finding is similar to those of previous studies, which have concluded that walkability increases the level of physical activity and active transportation. ${ }^{9}$ Walking is an easy way to be physically active. ${ }^{11}$ Walking is influenced by the built environment. ${ }^{6}$ The government should pay attention to walkability in neighborhoods to encourage walking. Moreover, physical activity has been found to be an important mediator between environment and health. ${ }^{5}$ The indicators of walkability reduce the risk of chronic diseases, including hypertension. ${ }^{21,} 22$ This study used OGD as resources, which are objective data. However, the results of objective and subjective measurements of walkability were closely correlated. Residents living in higher-walkability areas had lower BMI and risk factors for chronic diseases. ${ }^{20}$ Walkable neighborhoods encourage people to increase moderate to vigorous physical activity and achieve better health outcomes. ${ }^{23}$ People living in higher-walkability environments have lower cardio-metabolic risk.

We also demonstrated an application of OGD for the prevention of chronic diseases by environmental factors. The findings of this study, obtained through OGD analysis, could be used for health-related policy decision making and directing urban planning policies. OGD are a good medium between the government and citizens. Most importantly, OGD analysis can help create a better community. ${ }^{18}$

Nevertheless, there were three limitations to this study. The first is that the rate of outpatients with HTN was used, but this was not the prevalence of hypertensive diseases. In addition, because the source data were limited to OGD, the indicators of walkability were incomplete. Objective data were used in this study, but subjective data should also be considered in the future (e.g., perceived walkability, behavior factors, and physical activity). Finally, 
we hypothesized that other risk factors for NCDs, such as lifestyle and aging, would not vary between regions. This study focused on environmental factors.

This study has several implications. OGD are convenient for examining the outcome of policies. However it could be more transparent, accessible, usable, and free for citizens, stakeholders, and researchers. Because OGD were provided by different public departments, future OGD studies should integrate OGD on the same scale, such as counties and cities. The analytical results of OGD could offer recommendations for policy decision making. Furthermore, it is important to create high-walkability and supportive environments to promote public health. ${ }^{24}$ Urban development is also an important factor in walkable neighborhoods. To increase the WI, the governments should improve resident density, LUM, SC, safety, and socioeconomic status in the local environment. Walkability affects residents' intention to engage in outdoor activity. Higher-walkability environments could increase residents' physical activity and decrease the risk of chronic diseases. Due to its health benefits, walkability in administrative regions should be taken into consideration before public policy planning, including planning for sport, health, and urban design

\section{REFERENCES}

[1] World Health Organization, Non communicable diseases. Retrieved on Jul 05, 2016, from http://www.who.int/mediacentre/factsheets /fs $355 / \mathrm{en} /$.

[2] K. Atkinson, S. Lowe, and S. Moore, Human development, occupational structure and physical inactivity among 47 low and middle income countries. Preventive Medicine Reports, 3, p40-45, 2016. http://dx.doi.org/10.1016/j.pmedr.2015.11.009

[3] L. M. Braun, D. A. Rodríguez, K. R. Evenson, J. A. Hirsch, K. A. Moore, and A. V. Diez Roux, Walkability, Cardiometabolic risk factors: Cross-sectional and longitudinal associations from the Multi-Ethnic Study of Atherosclerosis. Health Place, 39, p9-17, 2016. http://dx.doi.org/10.1016/j.healthplace.2016.02.006

[4] C. D. Zick, K. R. Smith, J. X. Fan, B. B. Brown, I. Yamada, and L. Kowaleski-Jones, Running to the Store? The relationship between neighborhood environments and the risk of obesity. Social Science \& 
Medicine , 69(10), p1493-1500, 2009. http://dx.doi.org/10.1016/j. socscimed.2009.08.032

[5] V. Van Holle, J. Van Cauwenberg, D. Van Dyck, B. Deforche, N. Van de Weghe, and I. De Bourdeaudhuij, Relationship between neighborhood walkability and older adults' physical activity: results from the Belgian Environmental Physical Activity Study in Seniors (BEPAS Seniors). International Journal of Behavioral Nutrition and Physical Activity,11, p110, 2014. http://dx.doi.org/10.1186/s12966014-0110-3

[6] A. I. Ribeiro, A. Pires, M. S. Carvalho, and M. F. Pina, Distance to parks and non-residential destinations influences physical activity of older people, but crime doesn't: a cross-sectional study in a southern European city. BMC Public Health, 15, p593, 2015. http://dx.doi.org/10.1186/s12889-015-1879-y

[7] G. J. Andrews, E. Hall, B. Evans, and R. Colls, Moving beyond walkability: On the potential of health geography. Social Science \& Medicine,75(11), p1925-1932, 2012. http://dx.doi.org/10.1016/j. socscimed.2012.08.013

[8] J. I. Gilderbloom, W. W. Riggs, and W. L. Meares, Does walkability matter? An examination of walkability's impact on housing values, foreclosures and crime. Cities, 42 (part A), p13-24, 2015. http://dx.doi.org/10.1016/j.cities.2014.08.001

[9] A. Mahmood, H. Chaudhury, Y. L. Michael, M. Campo, K. Hay, and A. Sarte, A photovoice documentation of the role of neighborhood physical and social environments in older adults' physical activity in two metropolitan areas in North America. Social Science \& Medicine, 74(8), p 1180-1192, 2012. http://dx.doi.org/10.1016/j.socscimed. 2011.12.039

[10] H. M. Badland, M. Oliver, R. A. Kearns, S. Mavoa, K. Witten, M. J. Duncan, and G. D. Batty, Association of neighbourhood residence and preferences with the built environment, work-related travel behaviours, and health implications for employed adults: Findings from the URBAN study. Social Science \& Medicine, 75(8), p1469-1476, 2012. http://dx.doi.org/10.1016/j.socscimed.2012.05.029 
[11] J. A. Carlson, R. A. Remigio-Baker, C. A. M. Anderson, M. A. Adams, G. J. Norman, J. Kerr, M. H. Criqui, and M. Allison, Walking mediates associations between neighborhood activity supportiveness and BMI in the Women's Health Initiative San Diego cohort. Health \& Place, 38, p48-53, 2016. http://dx.doi.org/10.1016/j. healthplace.2016.01.001

[12] J. Gao, H. Fu, J. Li, and Y. Jia, Association between social and built environments and leisure-time physical activity among Chinese older adults - A multilevel analysis. BMC Public Health, 16(1), p.1317, 2015. http://dx.doi.org/10.1186/s12889-015-2684-3

[13] S. C. Brown et al., Neighborhood Greenness and Chronic Health Conditions in Medicare Beneficiaries, American Journal of Preventive Medicine, 51(1), p1-13, 2016. http://dx.doi.org/10.1016/j.amepre. 2016.02.008

[14] J. Veitch, G. Abbott, A. T. Kaczynski, S. A. Wilhelm Stanis, G. M. Besenyi, and K. E. Lamb, Park availability and physical activity, TV time, and overweight and obesity among women: Findings from Australia and the United States. Health \& Place, 38, p96-102, 2016. http://dx.doi.org/10.1016/j.healthplace.2015.12.004

[15] H. Chaudhury, M. Campo, Y. Michael, and A. Mahmood, Neighbourhood environment and physical activity in older adults., Social Science \& Medicine, 49, p104-113, 2015. http://dx.doi.org/10.1016/j.socscimed.2015.12.011

[16] G. S. Lovasi, M. D. M. Bader, J. Quinn, K. Neckerman, C. Weiss, and A. Rundle, Body mass index, safety hazards, and neighborhood attractiveness. American Journal of Preventive Medicine, 43(4), p378-384, 2012. http://dx.doi.org/10.1016/j.amepre.2012.06.018

[17] G. Green, J. Jackisch, and G. Zamaro, Healthy cities as catalysts for caring and supportive environments. Health Promotion International, 30, pi99-i107, 2015. http://dx.doi.org/10.1093/heapro/dav037

[18] M. Kassen, Globalization of e-government: open government as a global agenda; benefits, limitations and ways forward. Information Development, 30(1), p51-58, 2013. http://dx.doi.org/10.1177/ 0266666912473620 
[19] J. Attard, F. Orlandi, S. Scerri, and S. Auer, A systematic review of open government data initiatives. Government Information Quarterly., 32(4), p399-418, 2015. http://dx.doi.org/10.1016/j.giq.2015.07.006

[20] A. C. King et al., Aging in neighborhoods differing in walkability and income: Associations with physical activity and obesity in older adults. Social Science \& Medicine, 73(10), p1525-1533, 2011. http://dx.doi.org/10.1016/j.socscimed.2011.08.032

[21] F. Müller-Riemenschneider et al., Neighborhood walkability and cardiometabolic risk factors in Australian adults: an observational study. BMC Public Health, 13(1), p755, 2013. http://dx.doi.org/10. 1186/1471-2458-13-755

[22] L. D. Frank, J. Kerr, J. F. Sallis, R. Miles, and J. Chapman, A hierarchy of sociodemographic and environmental correlates of walking and obesity. Preventive Medicine, 47(2), p172-178, 2008. http://dx.doi.org/10.1016/j.ypmed.2008.04.004

[23] K. P. Arbour and K. A. Martin Ginis, The relationship between physical activity facility proximity and leisure-time physical activity in persons with spinal cord injury. Disability and Health Journal, 2(3), p128-135, 2009. http://dx.doi.org/10.1016/j.dhjo.2009.01.003

[24] N. T. Coffee, N. Howard, C. Paquet, G. Hugo, and M. Daniel, Is walkability associated with a lower cardiometabolic risk? Health \& Place, 21, p163-169, 2013. http://dx.doi.org/10.1016/j.healthplace. 2013.01.009 